\title{
Wind tunnel experiments on the effects of tillage ridge features on wind erosion horizontal fluxes
}

\author{
M. Kardous ${ }^{1}$, G. Bergametti ${ }^{2}$, and B. Marticorena ${ }^{2}$ \\ ${ }^{1}$ Institut des Régions Arides - El Fjé, 4119 Médenine, Tunisia \\ ${ }^{2}$ Laboratoire Interuniversitaire des Systèmes Atmosphériques, UMR CNRS 7583, Universités Paris7-Paris12, CMC, 61 \\ avenue du Général de Gaulle, 94010 Créteil cedex, France
}

Received: 11 April 2005 - Revised: 18 August 2005 - Accepted: 9 September 2005 - Published: 30 November 2005

\begin{abstract}
In addition to the well-known soil factors which control wind erosion on flat, unridged surfaces, two specific processes affect the susceptibility of tillage ridged surfaces to wind erosion: ridge-induced roughness and ridge- trapping efficiency.
\end{abstract}

In order to parameterize horizontal soil fluxes produced by wind over tillage ridges, eight-ridge configurations composed of sandy soil and exhibiting ridge heights to ridge spacing $(R H / R S)$ ratios ranging from 0.18 to 0.38 were experimented in a wind tunnel. These experiments are used to develop a parameterization of the horizontal fluxes over tillage ridged surfaces based only on the geometric characteristics of the ridges. Indeed, the key parameters controlling the horizontal flux, namely the friction velocity, threshold friction velocity and the adjustment coefficient, are derived through specific expressions, from ridge heights $(R H)$ and ridge spacing $(R S)$. This parameterization was evaluated by comparing the results of the simulations to an additional experimental data set and to the data set obtained by Hagen and Armbrust (1992). In both cases, predicted and measured values are found to be in a satisfying agreement.

This parameterization was used to evaluate the efficiency of ridges in reducing wind erosion. The results show that ridged surfaces, when compared to a loose, unridged soil surface, lead to an important reduction in the horizontal fluxes (exceeding 60\%). Moreover, the effect of ridges in trapping particles contributes for more than $90 \%$ in the flux reduction while the ridge roughness effect is weak and decreases when the wind velocity increases.

Keywords. Atmospheric composition and structure (Biosphere-atmosphere interactions) - Hydrology (Drought; Erosion and sedimentation)

Correspondence to: G. Bergametti

(bergametti@lisa.univ-paris12.fr)

\section{Introduction}

In arid and semi-arid regions, wind erosion is a serious environmental problem which needs appropriate measures for soil conservation (Pimentel et al., 1995; Saxton, 1995). It is more severe whenever the soil is loose, dry, bare, and periods with high wind velocities are frequent (Fryrear and Skidmore, 1985). The wind shear stress $(\tau)$ exerted on the soil surface controls the amount of transported soil. It depends on the wind friction velocity $\left(u_{*}\right)$ through the expression:

$\tau=\rho_{\text {air }} \cdot u_{*}^{2}$,

where

$\tau$ : wind shear stress $\left(\mathrm{m} \cdot \mathrm{l}^{-1} \cdot \mathrm{t}^{-2}\right)$;

$\rho_{\text {air }}$ air density $\left(\approx 0.00122 \mathrm{~g} . \mathrm{cm}^{-3}\right)$;

$u_{*}$ : wind friction velocity $\left(1 . t^{-1}\right)$.

In neutral conditions, according to Monin (1973) and Panofsky and Dutton (1984), $u_{*}$ can be retrieved from the wind velocity profile:

$u(z)=\frac{u_{*}}{k} \ln \frac{z-D}{z_{0}}$,

where

$u(z)$ : average wind velocity at height $\mathrm{z}\left(1 . \mathrm{t}^{-1}\right)$;

$k$ : Von Karman's constant (0.4);

$z_{0}$ : aerodynamic roughness length (1);

$D$ : displacement height (1).

Movement of soil particles is initiated when $u_{*}$ reaches the threshold value $\left(u_{* t}\right)$ required to counterbalance gravitational and electrostatic forces acting to maintain soil grains at the surface (Greeley and Iversen, 1985). These forces are dependent on soil characteristics (texture, composition, moisture, etc.) (Bagnold, 1941; Chepil, 1956; Chepil and Woodruff, 1963) and on the surface roughness elements (vegetation, gravel, pebbles, stones, etc.) which absorb a part of the wind momentum that will not be available to initiate particle motion. For given surface features, the duration and 


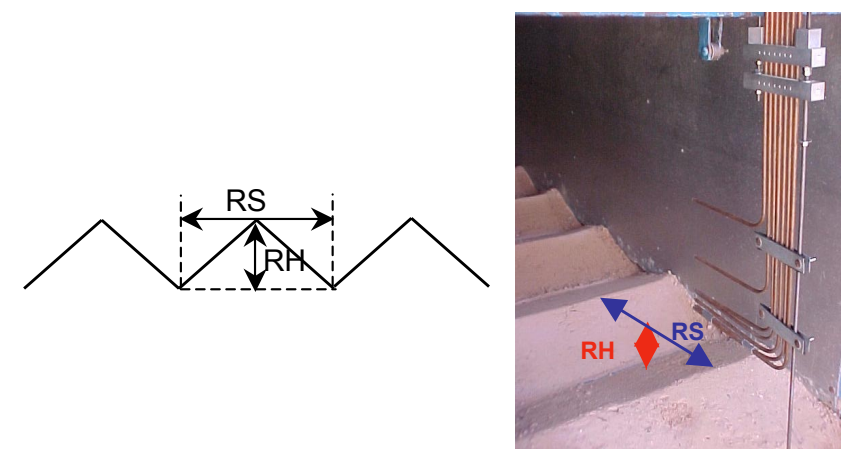

Fig. 1. Ridge geometric characteristics: Ridge spacing $(R S)$ and ridge heights $(R H)$.

the intensity of a wind erosion event depends mainly on how long and on how much the friction velocity exceeds the threshold friction velocity.

During wind erosion, particles move by creeping, saltation, or suspension. The transport mode of a particular particle is controlled by wind speed (Greeley and Iversen, 1985). Horizontal flux $(Q)$ is commonly used to quantify the amount of soil horizontally transported by wind. It represents the soil mass transported per second through a vertical surface of width unity and infinite height, perpendicular to the wind direction. It concerns mainly particles moving by creeping and saltation.

In arid and semi-arid cultivated areas, where conventional tillage is used, owing to limited vegetation cover, tillage ridges and soil cloddiness are the only soil roughness elements which could help in reducing wind erosion (Fryrear, 1985; Arika et al., 1986). In addition to the well-known soil factors, such as aggregates size distribution, crust, etc., which control wind erosion on flat, unridged surfaces, two specific processes affect the susceptibility to wind erosion of tillage ridged soils:

1. Since the ridges can affect the wind profile by increasing the surface aerodynamic roughness length, they influence $u_{*}$ and $u_{* t}$;

2. On ridged surfaces, a soil grain can be definitively be trapped in the furrow's bottom or can continue its movement, depending on its characteristic path length of saltation and on the ridge height and spacing. This affects the net budget of the soil mass exported from the field. Thus, the equations of horizontal fluxes for "natural roughness" are not appropriate to directly estimate the horizontal fluxes over cultivated areas.

Both processes are dependent on the geometrical characteristics of ridges: ridge height $(R H)$ and ridge spacing $(R S)$ (Kardous et al., 2005, this issue; Fryrear, 1984; Hagen and Armbrust, 1992) (Fig. 1).

Few works have been performed to investigate the relationship between tillage ridges and wind erosion. Fryrear (1984) simulated, in a wind tunnel, wind erosion from tillage ridges constructed from rough masonite (wood fiber board). Results showed that, at equal friction velocities, ridges reduced soil loss from the surface by $89 \%$ to $98 \%$ compared to unridged surfaces. Armbrust et al. (1964) measured, in a wind tunnel, soil losses from ridged soil, with ridge heights ranging from 1 to $20 \mathrm{~cm}$. Their results suggested that, for equal wind friction velocities and soil cloddiness, the presence of ridges could reduce total erosion up to $50 \%$ compared to unridged surfaces. These authors suggested a relationship linking soil loss (expressed in $\mathrm{kg} . \mathrm{m}^{-2}$ ) to $R H$, and percentage of soil cloddiness. Hagen and Armbrust (1992) have proposed relationships to evaluate the efficiency of ridges in reducing wind erosion. Their expression is based on the width of the trapping strip along wind direction, ridge heights and saltation discharge.

While these studies clearly demonstrate the efficiency of ridges in reducing wind erosion, no direct relationship, however, between $Q$ and the geometric characteristics of ridges ( $R H$ and $R S$ ) has been proposed. Thus, linking the horizontal fluxes to ridge characteristics is necessary for computing soil erosion fluxes over cultivated areas and also could be useful in designing and recommending tillage tools that reduce the soil susceptibility to wind erosion in semi-arid regions.

In this paper we report results from a wind tunnel experiment carried out in order to express the wind erosion horizontal flux as a function of ridge geometric characteristics. Section 2 describes the experimental procedure and briefly presents the literature reporting horizontal flux measurements over ridged surfaces. The experimental results, which include parameterisation of $Q$ and efficiency of ridges in reducing wind erosion, are presented in Sect. 3. Section 4 contains the summary and conclusion.

\section{Experimental procedure}

\subsection{Horizontal flux measurements}

A portable, push-type, non-recirculating wind tunnel, $7.32 \mathrm{~m}$ long, with a rectangular cross section $0.6 \mathrm{~m}$ wide and $0.8 \mathrm{~m}$ high, was used to evaluate soil horizontal flux over ridged bare surfaces. The wind-making equipment is composed of a gasoline engine and an axial-type ventilating fan. Air velocity is controlled by the speed of the engine. Airflow generated by a 6-blade fan was redistributed out by a series of screens in the transition section, connecting the fan to the duct, and by a aluminum, honeycomb-type air, straightner located between the duct and the transition section (Fig. 2).

The experiment involved 8 different sets of simulated ridges which were manually constructed. Ridges were made in a series of trays $52 \mathrm{~cm}$ wide, using appropriate steel patterns. A sandy soil composed of $30 \%$ of aggregates greater than $1 \mathrm{~mm}$ and smaller than $30 \mathrm{~mm}$ and of $70 \%$ of loose material with a very low amount of fine particles and organic matter, was used. Soil samples were taken from the top $10 \mathrm{~cm}$ from an agricultural field located $30 \mathrm{~km}$ to the southeast of Medenine (south Tunisia). The soil mass size distribution 


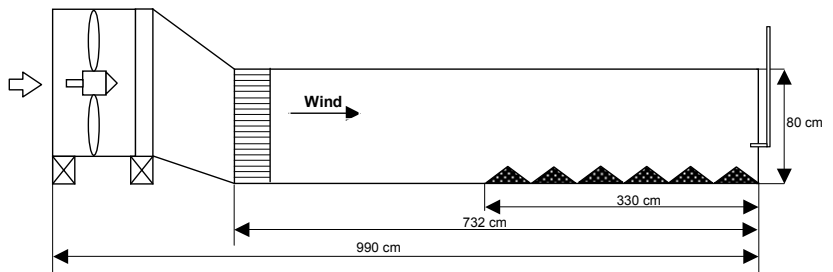

Fig. 2. Schematic view of the wind tunnel with the location of the tested sample.

obtained by dry sieving suggests that the fraction erodible by wind is bimodal. The first particle mode represents about $21 \%$ (std=9.8\%) of the total soil mass and is composed of particles having a median diameter of $60 \mu \mathrm{m}(\mathrm{std}=2 \mu \mathrm{m})$. The second particle mode represents about $79 \%$ (std=9.8\%) of the total soil mass and is composed of particles having a median diameter of $93 \mu \mathrm{m}(\mathrm{std}=4 \mu \mathrm{m})$. For each set of ridges, the tested soil was first air dried to less than $0.5 \%$ moisture content and then weighted. Ridges were installed perpendicularly to the airflow over about $3.3 \mathrm{~m}$ length, from the end of the tunnel working section. Ridge characteristics were chosen to be as representative as possible of ridges observed in the agricultural fields of Tunisia (North Africa): $R H$ and $R S$ ridge heights and spacing range, respectively, from 7.3 to $10.9 \mathrm{~cm}$ and 19 to $43 \mathrm{~cm}$, respectively, with ratios $R H / R S$ varying from 0.18 to 0.38 (Table 1 ).

Each set of ridges was exposed successively, during $15 \mathrm{~min}$, to three classes of free stream velocity: 4.5 to $6.5 \mathrm{~m} . \mathrm{s}^{-1}, 6.7$ to $8.5 \mathrm{~m} . \mathrm{s}^{-1}$ and 10 to $12 \mathrm{~m} . \mathrm{s}^{-1}$. For each free stream velocity, two replicates were performed. Wind velocity was determined by measuring the air dynamic pressure using an alcohol manometer connected to a static Pitot tube placed at a height of $42 \mathrm{~cm}$ from the furrow bottom on the vertical plan at the downwind end of the tunnel. Thereafter, the sand remaining on the working section of the wind tunnel was collected and re-weighted. The total soil loss was determined as the difference between the sand weight before and after the experiment. Wind erosion soil flux $(Q)$ was determined by dividing the total soil loss by the surface occupied by ridges and time for each experiment. This procedure was repeated for each ridge set, for the three tested velocities and the two replicates.

\subsection{Modeling procedure}

\subsubsection{Parameterization of the horizontal flux}

It is now generally recognized that $Q$ is proportional to the third power of $u_{*}$, and depends on $u_{* t}$ and on an adjustment coefficient $(a)$ which allows one to account for the erodibility of the soil. This erodibility mainly depends on the soil particle size and the surface properties (Williams, 1964; Gillette, 1974, 1979; Gillette and Stockton, 1989; Sörensen, 1985; Leys and Raupach, 1991; Shao et al., 1993).

Since the main objective of this study is to provide a parameterization of the horizontal soil fluxes produced by wind
Table 1. Characteristics (spacing: $R S$; height: $R H$ ) of ridges for each experimental set.

\begin{tabular}{cccc}
\hline$N^{\circ}$ & $R S(\mathrm{~cm})$ & $R H(\mathrm{~cm})$ & $R H / R S$ \\
\hline 1 & 43.0 & 9.6 & 0.22 \\
2 & 40.0 & 7.3 & 0.18 \\
3 & 34.6 & 9.6 & 0.28 \\
4 & 34.3 & 10.9 & 0.32 \\
5 & 28.6 & 10.5 & 0.37 \\
6 & 27.6 & 7.7 & 0.28 \\
7 & 24.0 & 7.3 & 0.30 \\
8 & 19.1 & 7.3 & 0.38 \\
\hline
\end{tabular}

over tillage ridges, the parameters $u_{*}, u_{* t}$ and $a$ were required for each tested configuration. For this purpose, we first have used a classical expression of the horizontal flux developed by Lettau and Lettau (1978) (Eq. 3), to reproduce our measurements. In a second step, we investigate a relationship linking $u_{*}, u_{* t}$ and $a$ to the geometric characteristics of ridges: $R H$ and $R S$ (Eq. 4).

$Q=a \cdot u_{*}^{2} \cdot\left(u_{*}-u_{* t}\right)$

$\left(a, u_{*}, u_{* t}\right)=f(R H, R S)$

\subsubsection{Wind friction velocity $\left(\mathrm{u}_{*}\right)$}

In a previous work (Kardous et al., 2005, this issue), wind tunnel experiments involving 11 sets of simulated ridges were carried out to determine the relationships between $z_{0}$ and the geometric characteristics of tilled ridges. Depending on the tested ridge configurations, 6 to 12 wind velocity measurements, located in the log-law region, were used to fit wind profiles, in order to determine, aerodynamic roughness lengths $\left(z_{0}\right.$ and $\left.D\right)$ and wind friction velocity. For eight of the eleven sets, measurements of horizontal fluxes have been performed. By using their results and those from Hagen and Armbrust (1992), Kardous et al. (2005, this issue) show that the aerodynamic roughness length over ridged surfaces can be related to the geometric characteristics of the ridges:

$z_{0}=1.2736 \cdot \frac{R H^{2}}{R S}-0.005$,

where $z_{0}, R H$ and $R S$ were expressed in meters.

\subsubsection{Threshold friction velocity $\left(\mathrm{u}_{* t}\right)$}

The threshold wind friction velocity $\left(u_{* t}\right)$ is more complex to estimate, since it depends on the degree of aggregation of the ridged soil and, in particular, on the size and the location of the loose particles with regard to the ridge's relief. Indeed, a range of threshold friction velocities exists, and it seems more relevant to use the value of the threshold friction velocity at which saltation is active across the entire surface instead of the one at which the first particles begin to move. Practically, it is difficult to precisely determine this value by 
Table 2. Experimental data for horizontal flux measurements.

\begin{tabular}{|c|c|c|c|c|c|c|c|c|c|c|c|c|c|c|c|c|}
\hline \multirow{3}{*}{$\begin{array}{l}N^{\circ} \\
(\mathrm{cm})\end{array}$} & \multirow{2}{*}{\multicolumn{4}{|c|}{ Ridge characteristics }} & \multicolumn{4}{|c|}{ First wind velocity class* } & \multicolumn{4}{|c|}{ Second wind velocity class* } & \multicolumn{4}{|c|}{ Third wind velocity class* } \\
\hline & & & & & \multicolumn{2}{|c|}{ First replicate } & \multicolumn{2}{|c|}{ Second replicate } & \multicolumn{2}{|c|}{ First replicate } & \multicolumn{2}{|c|}{ Second replicate } & \multicolumn{2}{|c|}{ First replicate } & \multicolumn{2}{|c|}{ Second replicate } \\
\hline & $\begin{array}{c}R S \\
(\mathrm{~cm})\end{array}$ & $\begin{array}{l}R H \\
(\mathrm{~cm})\end{array}$ & $\begin{array}{c}z_{0} \\
(\mathrm{~cm})\end{array}$ & $\begin{array}{c}D \\
\left(\mathrm{~cm} \cdot \mathrm{s}^{-1}\right)\end{array}$ & $\begin{array}{c}u \\
\left(\mathrm{~g} . \mathrm{cm}^{-1} \cdot \mathrm{s}^{-1}\right)\end{array}$ & $\begin{array}{c}Q \\
\left(\mathrm{~cm} \cdot \mathrm{s}^{-1}\right)\end{array}$ & $\begin{array}{c}u \\
\left(\mathrm{~g} \cdot \mathrm{cm}^{-1} \cdot \mathrm{s}^{-1}\right)\end{array}$ & $\begin{array}{c}Q \\
\left(\mathrm{~cm} \cdot \mathrm{s}^{-1}\right)\end{array}$ & $\begin{array}{c}u \\
\left(\mathrm{~g} \cdot \mathrm{cm}^{-1} \cdot \mathrm{s}^{-1}\right)\end{array}$ & $\begin{array}{c}Q \\
\left(\mathrm{~cm} \cdot \mathrm{s}^{-1}\right)\end{array}$ & $\begin{array}{c}u \\
\left(\mathrm{~g} \cdot \mathrm{cm}^{-1} \cdot \mathrm{s}^{-1}\right)\end{array}$ & $\begin{array}{c}Q \\
\left(\mathrm{~cm} \cdot \mathrm{s}^{-1}\right)\end{array}$ & $\begin{array}{c}u \\
\left(\mathrm{~g} \cdot \mathrm{cm}^{-1} \cdot \mathrm{s}^{-1}\right)\end{array}$ & $\begin{array}{c}Q \\
\left(\mathrm{~cm} \cdot \mathrm{s}^{-1}\right)\end{array}$ & $\begin{array}{c}u \\
\left(\mathrm{~g} \cdot \mathrm{cm}^{-1} \cdot \mathrm{s}^{-1}\right)\end{array}$ & $Q$ \\
\hline 1 & 43.0 & 9.6 & 2.09 & 1.96 & 596 & 0.0252 & 653 & 0.0279 & 818 & 0.0452 & 793 & 0.0568 & 1149 & 0.1563 & 992 & 0.1374 \\
\hline 2 & 40.0 & 7.3 & 1.44 & 4.83 & 552 & 0.0075 & 637 & 0.0182 & 818 & 0.0500 & 806 & 0.0382 & 1103 & 0.1448 & 1153 & 0.1170 \\
\hline 3 & 34.6 & 9.6 & 2.97 & 3.82 & 504 & 0.0135 & 561 & 0.0278 & 740 & 0.0586 & 812 & 0.0654 & 1027 & 0.1534 & 1099 & 0.2007 \\
\hline 4 & 34.3 & 10.9 & 4.61 & 2.20 & 462 & 0.0304 & 552 & 0.0300 & 726 & 0.0554 & 754 & 0.0609 & 1007 & 0.1719 & 1017 & 0.1596 \\
\hline 5 & 28.6 & 10.5 & 4.20 & 3.39 & 504 & 0.0109 & 552 & 0.0280 & 698 & 0.0485 & 761 & 0.0603 & 1085 & 0.1455 & 1108 & 0.1627 \\
\hline 6 & 27.6 & 7.7 & 2.04 & 1.80 & 542 & 0.0122 & 604 & 0.0144 & 780 & 0.0503 & 754 & 0.0474 & 1108 & 0.1177 & 1175 & 0.1383 \\
\hline 7 & 24.0 & 7.3 & 2.65 & 3.45 & 552 & 0.0118 & 587 & 0.0170 & 761 & 0.0396 & 806 & 0.0471 & 1085 & 0.1145 & 1183 & 0.1282 \\
\hline 8 & 19.1 & 7.3 & 2.39 & 3.14 & 542 & 0.0069 & 637 & 0.0132 & 780 & 0.0322 & 787 & 0.0373 & 1149 & 0.0944 & 1162 & 0.0951 \\
\hline 9 & Unrid & $\mathrm{d}$ surface & 0.007 & - & 637 & 0.0279 & 613 & 0.0202 & 878 & 0.0403 & 831 & 0.0399 & 1209 & 0.1346 & 1217 & 0.1415 \\
\hline
\end{tabular}

* Wind velocities were measured at $\mathrm{z}=42 \mathrm{~cm}$ (i.e. into the free stream zone). See text for the details of the wind velocity classes.

Table 3. Calculated wind friction threshold velocities for aeolian erosion for the eight experimental ridge configurations.

\begin{tabular}{cccc}
\hline $\begin{array}{c}R S \\
(\mathrm{~cm})\end{array}$ & $\begin{array}{c}R H \\
(\mathrm{~cm})\end{array}$ & $\begin{array}{c}z_{0} \\
(\mathrm{~cm})\end{array}$ & $\begin{array}{c}u_{* t} \\
\left(\mathrm{~cm} . \mathrm{s}^{-1}\right)\end{array}$ \\
\hline 43.0 & 9.6 & 2.09 & 57.4 \\
40.0 & 7.3 & 1.44 & 49.5 \\
34.6 & 9.6 & 2.97 & 38.7 \\
34.3 & 10.9 & 4.61 & 16.8 \\
28.6 & 10.5 & 4.20 & 44.3 \\
27.6 & 7.7 & 2.04 & 41.3 \\
24.0 & 7.3 & 2.65 & 26.9 \\
19.1 & 7.3 & 2.39 & 35.7 \\
\hline
\end{tabular}

direct observations. Hence, we adopt the approach recommended by Hagen (2001), which consists of using the flux $Q$ measured at two or more wind speeds in the transport capacity equation and to solve it for the unknown threshold friction velocity.

Thus, for a given soil ridge configuration and for two different friction velocities, $u_{* i}$ and $u_{* j}$, the measured fluxes were, respectively, $Q_{i}$ and $Q_{j}$.

Using Eq. (3) and assuming that the coefficient $a$ in Eq. (3) only depends on the ridge geometric characteristics, we can write:

$$
\frac{Q_{i} / u_{* i}^{2}}{Q_{j} / u_{* j}^{2}}=\frac{u_{* i}-u_{* t}}{u_{* j}-u_{* t}}
$$

in which $u_{* t}$ is the only unknown parameter.

For each ridge configuration, six series of horizontal flux measurements performed at various wind friction velocities are available. This leads to a system of 15 Eqs. (6) which were solved using an iterative procedure based on the leastsquares regression method.

\subsubsection{The adjustment coefficient (a)}

Since the threshold friction velocities $u_{* t}$ were determined, it is possible to compare the measured fluxes to Eq. (3). Thus, we fitted $Q / u_{*}^{2}$ to $a \cdot\left(u_{*}-u_{* t}\right)$ for all ridge configurations and friction velocities:

$\frac{Q}{u_{*}^{2}}=a \cdot\left(u_{*}-u_{* t}\right)$,

From this equation, the coefficient $a$ can be easily determined by a least-squares regression method.

\section{Results and discussion}

Experimental data, including ridge characteristics $(R S, R H$, $z_{0}$ and $D$ ), wind velocity $(u)$ and measured flux $(Q)$, are reported in Table 2 . For the whole data, the wind velocity ranged from 462 to $1217 \mathrm{~cm} . \mathrm{s}^{-1}$, and the measured flux from 0.0069 to $0.2007 \mathrm{~g} . \mathrm{cm}^{-1} \cdot \mathrm{s}^{-1}$. Obviously, for all the tested configurations, $Q$ increases with wind velocity: when wind velocity increases nearly 2 times, $Q$ increases by a factor of 5 to 15 , depending on the ridge configuration.

\subsection{Parameterization of the horizontal flux}

The calculated wind threshold friction velocities $u_{* t}$ are given in Table 3 for each ridge configuration. These wind threshold friction velocities vary from 16.8 to $57.4 \mathrm{~cm} . \mathrm{s}^{-1}$.

For approximately the same ridge spacing $(R S), u_{* t}$ decreases when ridge heights increase and conversely for the same $R H, u_{* t}$ increases with ridge spacing. By plotting the calculated $u_{* t}$ versus the ratio of aerodynamic roughness length to the ridge height, $z_{0} / R H$, a linear relationship (12) $(r=0.96)$ was obtained (Fig. 3).

$u_{* t}=-162.61 \cdot \frac{z_{0}}{R H}+86.871$.

The configuration corresponding to ridges spaced $28.6 \mathrm{~cm}$ wide and $10.5 \mathrm{~cm}$ high (grey point in Fig. 3) has been discarded from the linear regression. We have to note that this configuration exhibits the highest relative difference $(61 \%)$ between the saltation fluxes measured for the two replicates: this probably affects significantly the precision of the calculated threshold friction velocity. 


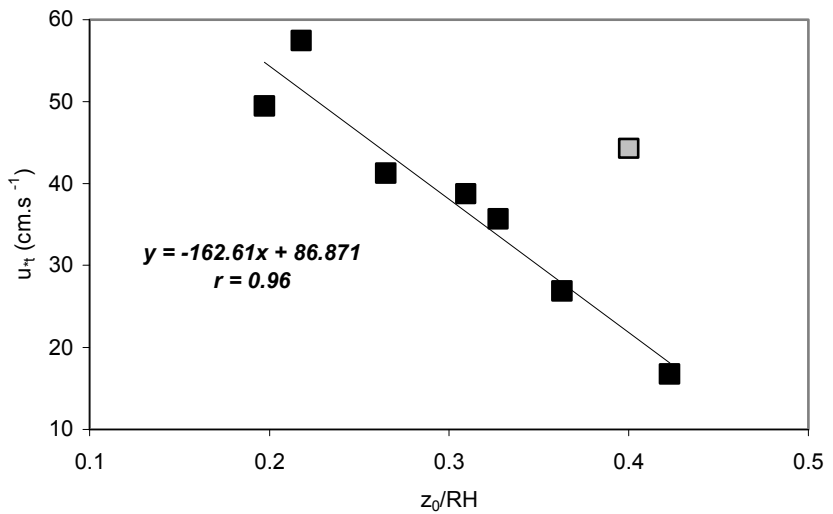

Fig. 3. Calculated threshold wind friction velocities for aeolian erosion versus $z_{0} / R H$.

Since $z_{0}$ was found to be correlated with $R S$ and $R H$ (Eq. 5), $u_{* t}$ can be expressed in terms of ridge height $(R H)$ and ridge spacing $(R S)$ only:

$u_{* t}=-207.1 \cdot \frac{R H}{R S}+\frac{81.305}{R H}+86.871$.

This relationship, only applicable over the range of $R H / R S$ (0.18-0.38) used for its determination, suggests that the threshold friction velocity increases when $R H / R S$ decreases. It also indicates that, for a given $R H / R S$ ratio, $u_{* t}$ decreases when $R H$ increases.

For each ridge configuration, the adjustment coefficient (a) was determined by a least-squares regression method and highly significant correlation coefficients (except for the ridge configuration $(R H=9.6$ and $R S=43 \mathrm{~cm})$ ) were obtained (Table 4).

Given that coefficient $a$ is not constant and varies by a factor of 3, depending on the configuration, we investigated its dependence upon the geometric characteristics of ridges. As showen in Fig. 4, an excellent agreement $(r=0.92)$ is found between $a$ and $R H / R S$, leading to the following equation:

$a=-3.10 \cdot 10^{-7} \cdot \frac{R H}{R S}+1.39 \cdot 10^{-7}\left(\mathrm{~g} . \mathrm{cm}^{-4} \cdot \mathrm{s}^{2}\right)$

The coefficient $a$ decreases when $R H / R S$ increases, suggesting that the horizontal flux is greater for small ridges, largely spaced. This seems to be consistent statement, since, for very low $R H$ and very large $R S$, the surface tends towards a smooth surface.

This result also reinforces our confidence in the assumption made to determine $u_{* t}$, since $a$ can be predicted from only the geometrical characteristics of the ridges and does not seem to be too much dependent on $u_{*}$. It should be noted that, despite a low correlation coefficient (see Table 4), the value of $a$ for the ridge configuration ( $R H=9.6$ and $R S=43 \mathrm{~cm}$ ) follows the same tendency as that obtained for the other configurations. Therefore, this data set will be retained for the forthcoming analyses.

From the parameterizations established to retrieve the coefficient $a$ and $u_{* t}$ from $R H$ and $R S$, a complete parameterization of the erosion flux can be proposed by including

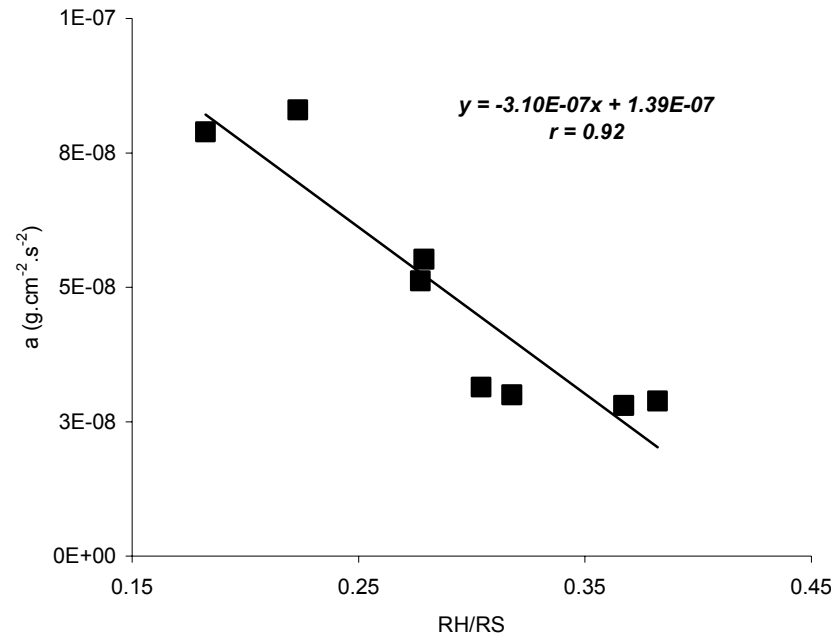

Fig. 4. Coefficient $a$ versus $R H / R S$.

Table 4. Values of the coefficient $a$ for the different experimental ridges.

\begin{tabular}{cccc}
\hline$R S(\mathrm{~cm})$ & $R H(\mathrm{~cm})$ & $a\left(\mathrm{~g} . \mathrm{cm}^{-4} . s^{2}\right)$ & $r$ \\
\hline 43.0 & 9.6 & $8.3 \mathrm{E}-08$ & 0.53 \\
40.0 & 7.3 & $7.9 \mathrm{E}-08$ & 0.90 \\
34.6 & 9.6 & $5.1 \mathrm{E}-08$ & 0.94 \\
34.3 & 10.9 & $3.0 \mathrm{E}-08$ & 0.99 \\
28.6 & 10.5 & $2.8 \mathrm{E}-08$ & 0.91 \\
27.6 & 7.7 & $5.5 \mathrm{E}-08$ & 0.78 \\
24.0 & 7.3 & $3.1 \mathrm{E}-08$ & 0.93 \\
19.1 & 7.3 & $2.9 \mathrm{E}-08$ & 0.91 \\
\hline
\end{tabular}

in Eq. (3) the parameterizations previously developed for $z_{0}, u_{* t}$ and $a$ (Eqs. 5, 8 and 10). Figure 5 shows a very good agreement between the erosion fluxes calculated using this equation and the measured ones, as well as for the low and high fluxes, regardless of the geometrical characteristics of the ridges: the correlation coefficient is highly significant $(r=0.96)$ and the slope is close to $1(1.07)$.

\subsection{Validation}

In order to test the capability of this equation to simulate the wind erosion fluxes, two additional data sets, not used to establish the previous parameterizations, have been considered.

\subsubsection{Additional data set}

First, we calculated the wind erosion fluxes induced by four other ridge configurations, for which only the mean wind velocity, $u$, the measured horizontal fluxes, $Q$ and the geometric characteristics $R H$ and $R S$, were known. Hence, we determined the key parameters of the proposed parameterization which are the wind friction velocity, $u_{*}$, the wind threshold friction velocity, $u_{* t}$ and the adjustment coefficient, $a$ (Table 5). 
Table 5. Geometric characteristics of the ridges for the additional data set and computed values for $u_{*}, u_{* t}$ and $a$.

\begin{tabular}{cccccc}
\hline $\begin{array}{c}R S \\
(\mathrm{~cm})\end{array}$ & $\begin{array}{c}R H \\
(\mathrm{~cm})\end{array}$ & $\begin{array}{c}u_{(42 \mathrm{~cm})}\left(\mathrm{cm} . \mathrm{s}^{-1}\right) \\
\left(\begin{array}{c}u_{*} \\
\left(\mathrm{~cm} . \mathrm{s}^{-1}\right)\end{array}\right.\end{array} \begin{array}{c}u_{* t} \\
\left({\left.\mathrm{~cm} . \mathrm{s}^{-1}\right)}^{-1}\right)\end{array}$ & $\begin{array}{c}a \\
\left(\mathrm{~g} . \mathrm{cm}^{-4} . s^{2}\right) \\
\text { from Eq. }(10)\end{array}$ \\
\hline 41.7 & 11.5 & 514 & 85.6 & 36.8 & $5.35 \mathrm{E}-08$ \\
41.7 & 11.5 & 613 & 102.1 & 36.8 & $5.35 \mathrm{E}-08$ \\
41.7 & 11.5 & 668 & 111.4 & 36.8 & $5.35 \mathrm{E}-08$ \\
41.7 & 11.5 & 712 & 118.7 & 36.8 & $5.35 \mathrm{E}-08$ \\
41.7 & 11.5 & 997 & 166.2 & 36.8 & $5.35 \mathrm{E}-08$ \\
41.7 & 11.5 & 1061 & 176.9 & 36.8 & $5.35 \mathrm{E}-08$ \\
50.0 & 9.4 & 587 & 75.7 & 56.6 & $8.07 \mathrm{E}-08$ \\
50.0 & 9.4 & 604 & 77.9 & 56.6 & $8.07 \mathrm{E}-08$ \\
50.0 & 9.4 & 831 & 107.1 & 56.6 & $8.07 \mathrm{E}-08$ \\
50.0 & 9.4 & 806 & 103.9 & 56.6 & $8.07 \mathrm{E}-08$ \\
50.0 & 9.4 & 1192 & 153.6 & 56.6 & $8.07 \mathrm{E}-08$ \\
50.0 & 9.4 & 1144 & 147.5 & 56.6 & $8.07 \mathrm{E}-08$ \\
28.5 & 9.4 & 533 & 87.9 & 27.2 & $3.68 \mathrm{E}-08$ \\
28.5 & 9.4 & 579 & 95.5 & 27.2 & $3.68 \mathrm{E}-08$ \\
28.5 & 9.4 & 780 & 128.7 & 27.2 & $3.68 \mathrm{E}-08$ \\
28.5 & 9.4 & 719 & 118.6 & 27.2 & $3.68 \mathrm{E}-08$ \\
28.5 & 9.4 & 1076 & 177.4 & 27.2 & $3.68 \mathrm{E}-08$ \\
28.5 & 9.4 & 1113 & 183.5 & 27.2 & $3.68 \mathrm{E}-08$ \\
22.9 & 7.2 & 552 & 79.0 & 33.0 & $4.15 \mathrm{E}-08$ \\
22.9 & 7.2 & 637 & 91.2 & 33.0 & $4.15 \mathrm{E}-08$ \\
22.9 & 7.2 & 837 & 119.8 & 33.0 & $4.15 \mathrm{E}-08$ \\
22.9 & 7.2 & 787 & 112.6 & 33.0 & $4.15 \mathrm{E}-08$ \\
22.9 & 7.2 & 1126 & 161.2 & 33.0 & $4.15 \mathrm{E}-08$ \\
22.9 & 7.2 & 1144 & 163.7 & 33.0 & $4.15 \mathrm{E}-08$ \\
\hline & & & & & \\
\hline
\end{tabular}

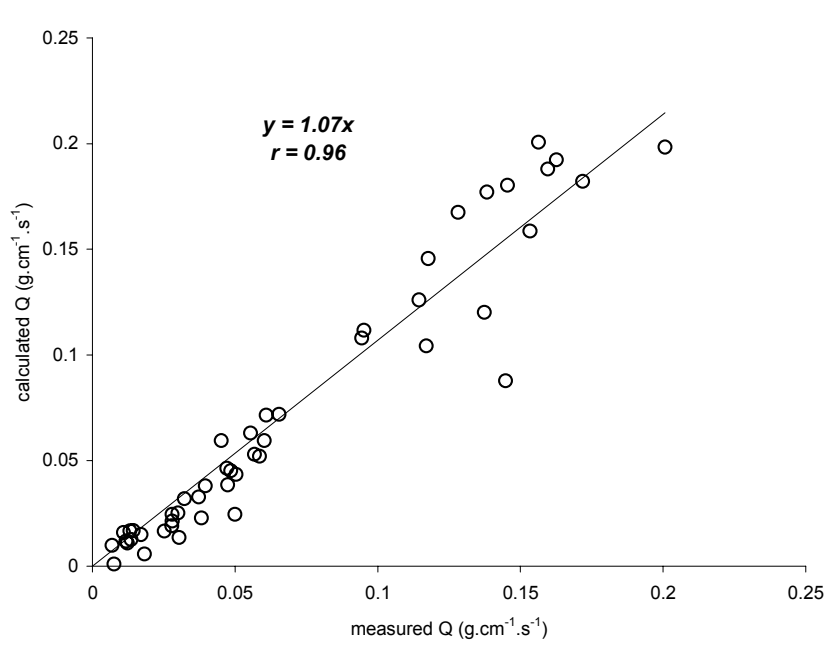

Fig. 5. Comparison between calculated and measured erosion fluxes for the eight ridges data sets $(n=48)$.

Referring to Eq. (2), wind friction velocity, $u_{*}$, depends on the mean wind velocity $u(z)$, aerodynamic roughness length, $z_{0}$ and zero plane displacement height, $D$.

Since Eq. (5) provides only $z_{0}$, we evaluated the sensibility of the friction velocity $u_{*}$ to different values of the displacement height, $D$. In the case of the eight tested ridge configurations, the values of $D$ vary from 1.8 to $4.8 \mathrm{~cm}$. Therefore, wind friction velocities, $u_{*}$, were calculated first for values of $D$ and $z_{0}$, ranging, respectively, from 1 to $5 \mathrm{~cm}$, and from 1 to $6 \mathrm{~cm}$. The results were compared to $u_{*}$ calculated with a constant $D=3 \mathrm{~cm}$ (i.e. the mean value of the displacement height used for the previous experimental sets).

Figure 6 shows that using a mean value $D=3 \mathrm{~cm}$ generates errors less than $\pm 3 \%$ on $u_{*}$, regardless of the values of $D$ and $z_{0}$. Thus, a value of the zero plane displacement height $D$ equal to $3 \mathrm{~cm}$ was adopted to calculate, using Eq. (2), the wind friction velocity, $u_{*}$, for the four additional ridge configurations.

The threshold friction velocity, $u_{* t}$, and the adjustment coefficient, $a$, can be computed using, respectively, Eqs. (9) and (10).

The calculated and measured horizontal fluxes for this additional experimental data set are reported in Fig. 7. A very good agreement is observed, with the correlation coefficient being very high $(r=0.99)$ and the slope being equal to 1.13 (Fig. 7).

\subsubsection{Comparison with the Hagen and Armbrust (1992) data set}

In a second step, we tested the capability of the proposed parameterization to predict existing wind erosion flux measurements. The only data set available in the literature was 


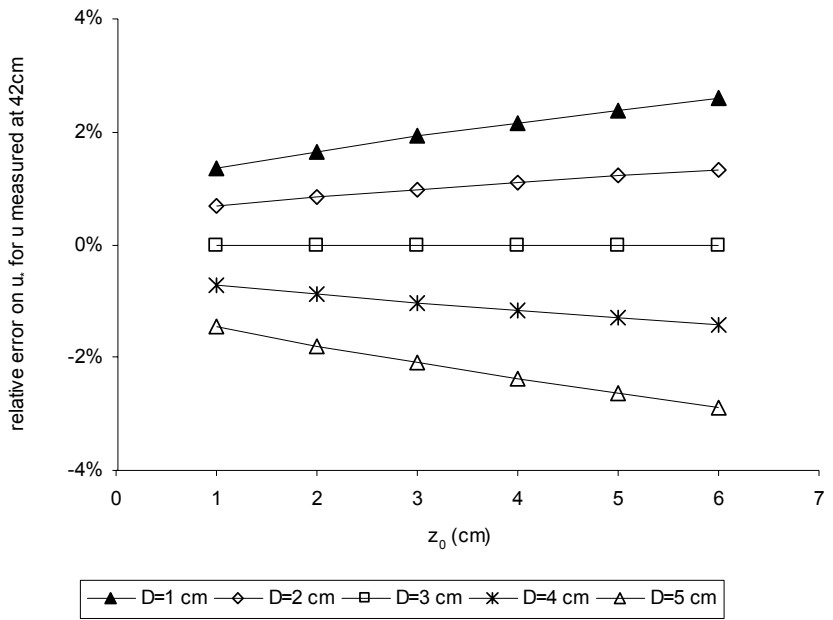

Fig. 6. Sensitivity of $u_{*}$ (expressed in \%) to the displacement height value $D$ for different $z_{0}$ (relative error computed using $D=3 \mathrm{~cm}$ as a reference value).

obtained by Hagen and Armbrust (1992). These authors have measured the wind friction velocity and horizontal fluxes for different ridge configurations. Note that, compared to our data set, the soil texture and the operational conditions (windtunnel, techniques for measurements, etc.) were different. The soil used by Hagen and Armbrust (1992) is a sandy soil composed of a mixture of gravel, 2 to $6 \mathrm{~mm}$ in diameter, and quartz sand, 0.29 to $0.42 \mathrm{~mm}$.

We calculated first $z_{0}, u_{* t}, a$ and then the wind erosion flux, $Q$, using the method described for our additional data set. Once again, Fig. 8, which includes all the data sets, shows that the proposed parameterization reproduces quite well the Hagen and Armbrust (1992) data. The correlation coefficient and slope remained highly significant, with values similar to those previously obtained $(r=0.97$, slope $=1.10)$. When considering only the Hagen and Armbrust (1992) data set (10 values), the correlation coefficient is slightly lower $(r=0.78$; $\mathrm{p}<0.05)$ and the slope is slightly higher (1.22). The satisfying agreement obtained with this data set suggests that the developed parameterization can be applied for $R H / R S$ as low as 0.05, since the Hagen and Armbrust (1992) RH/RS range from 0.05 to 0.21 .

\subsection{Efficiency of ridges in reducing wind erosion}

To compare the behavior of tillage ridged and unridged surfaces with regard to the wind erosion process, wind erosion fluxes measured for an equivalent unridged surface are needed. Thus, we measured wind erosion fluxes from a flat surface composed of the same sandy soil used for the ridge configurations previously tested. The aerodynamic roughness length of this unridged surface $\left(z_{0 s}\right)$ was measured from a wind profile performed for this purpose. Its value was found to be of the order of $0.007 \mathrm{~cm}$. Wind erosion fluxes were determined for six different friction velocities, as it was previously performed for the ridged surfaces. The threshold

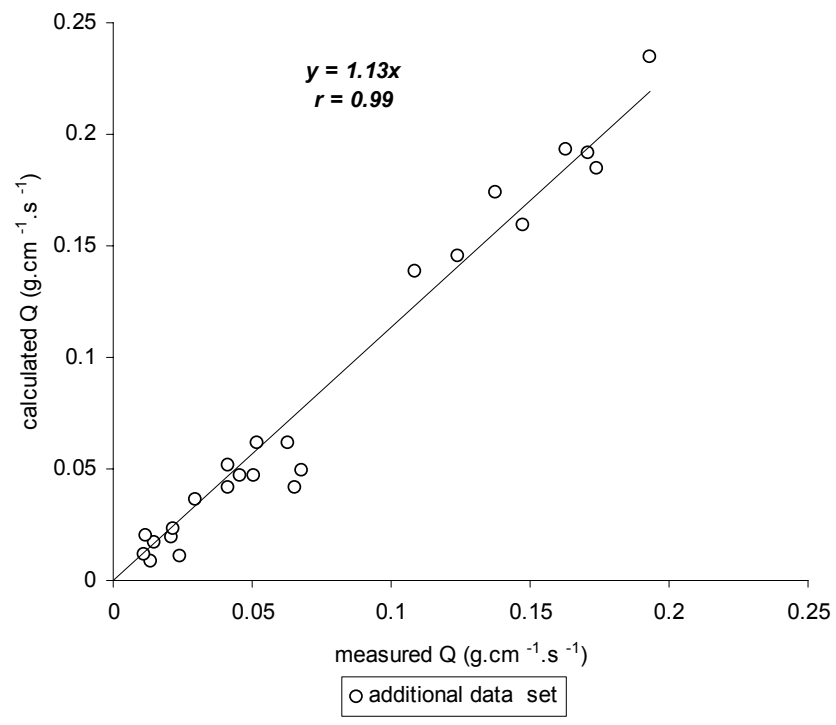

Fig. 7. Comparison between calculated and measured erosion fluxes for the additional data set $(n=24)$.

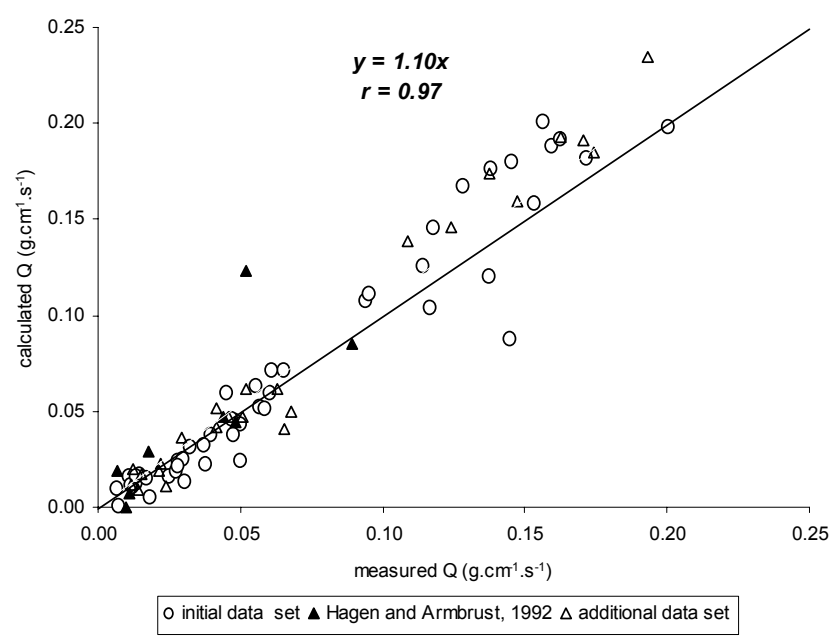

Fig. 8. Comparison between calculated and measured erosion fluxes including the data from Hagen and Armbrust (1992) $(n=80)$.

friction velocity, $\left(u_{* t s}\right)$, and the adjustment coefficient, $a_{s}$, were determined, as described in Sects. 3.2 and 3.3, respectively. Their calculated values were determined to be, respectively, $20.9 \mathrm{~cm} . \mathrm{s}^{-1}$ and $1.39 .10^{-6} \mathrm{~g} . \mathrm{cm}^{-4} . \mathrm{s}^{2}$.

A satisfying agreement is obtained between the measured flux and the flux calculated using Eq. (3) $(r=0.99 ; \mathrm{P}<0.001)$ (Fig. 9). A 7\% error, on average, can be estimated from the slope of the regression.

Since the calculated wind erosion fluxes agree well with experimental data, for both ridged and unridged surfaces, they can be used to compare the behavior of ridged and unridged surfaces with regard to the wind erosion.

Figure 10 reports the values of the horizontal fluxes computed for the various ridge configurations $\left(Q_{r}\right)$ and for the 


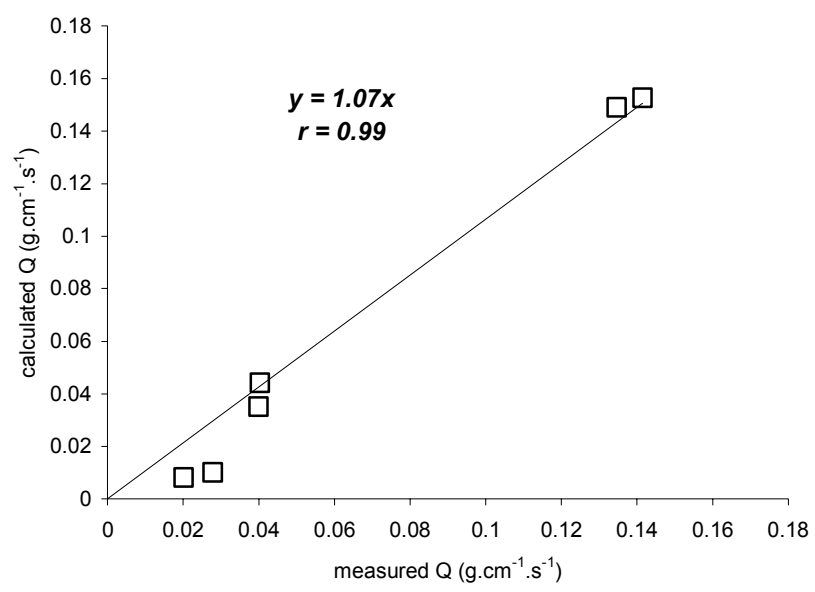

Fig. 9. Measured versus calculated fluxes for the unridged surface.

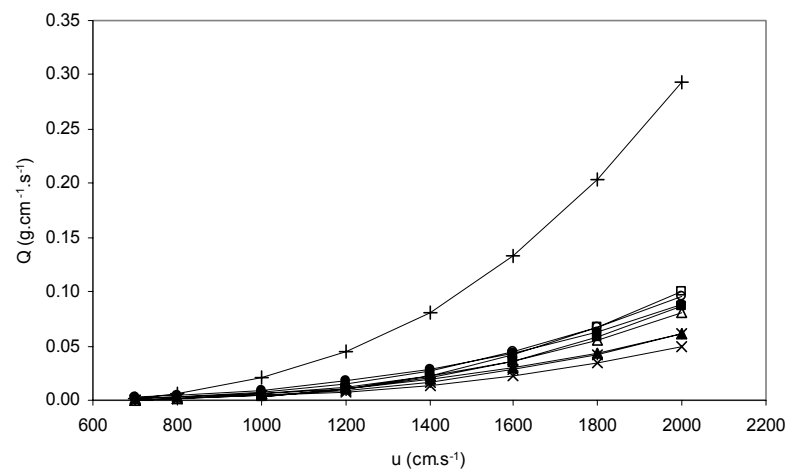

ㄴ $\mathrm{RS}=43.0 \mathrm{~cm} ; \mathrm{RH}=9.6 \mathrm{~cm} \rightarrow \mathrm{RS}=40.0 \mathrm{~cm} ; \mathrm{RH}=7.3 \mathrm{~cm} \quad \longrightarrow \mathrm{RS}=34.6 \mathrm{~cm} ; \mathrm{RH}=9.6 \mathrm{~cm}$ - $\mathrm{RS}=34.3 \mathrm{~cm} ; \mathrm{RH}=10.9 \mathrm{~cm} \rightarrow \mathrm{RS}=28.6 \mathrm{~cm} ; \mathrm{RH}=10.5 \mathrm{~cm} \triangle \mathrm{RS}=27.6 \mathrm{~cm} ; \mathrm{RH}=7.7 \mathrm{~cm}$ ^ $\mathrm{RS}=24.0 \mathrm{~cm} ; \mathrm{RH}=7.3 \mathrm{~cm} \quad$ × $\mathrm{RS}=19.1 \mathrm{~cm} ; \mathrm{RH}=7.3 \mathrm{~cm}$ —Unridged surface

Fig. 10. Calculated erosion fluxes as a function of the wind velocity at $10 \mathrm{~m}$.

unridged surface $\left(Q_{s}\right)$. First, when looking at the horizontal fluxes over the various ridge configurations, we can notice that these horizontal fluxes vary only by a factor of 2 . This suggests that the geometric characteristics of the ridges have a significant but limited effect on the horizontal fluxes. Indeed, this factor of 2 has to be compared to the value of the horizontal flux over the unridged surface, which is about 3 times greater than the strongest horizontal flux measured over a ridged surface. This clearly suggests that the ridges, whatever their geometric characteristics, are very efficient in reducing wind erosion over loose soil.

\subsubsection{Total reduction of wind erosion flux}

Total reduction of wind erosion flux due to both ridge roughness and trapping processes can be estimated through the difference between the horizontal fluxes computed for the unridged surface and those computed for the various ridge configurations $\left(Q_{s}-Q_{r}\right)$, while the ratio $\left(Q_{s}-Q_{r}\right) / Q_{s}$ expresses the relative total reduction in the horizontal flux due to the ridges.

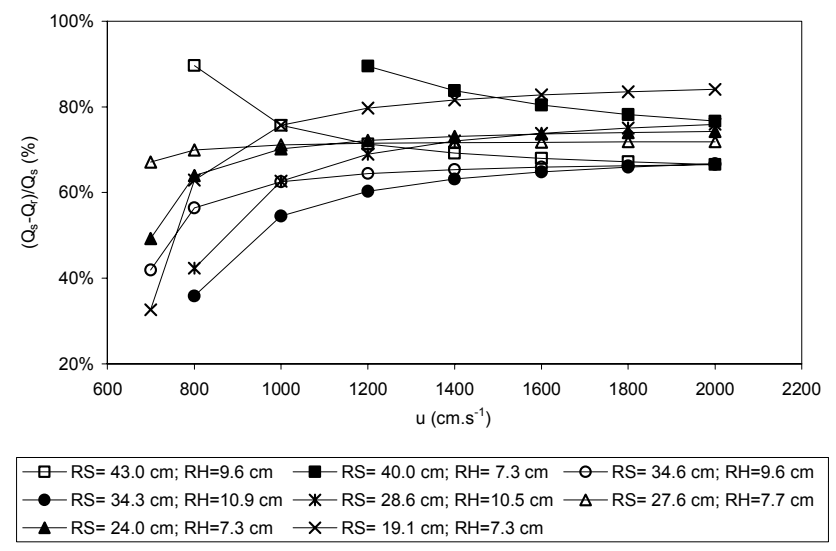

Fig. 11. Total flux reduction relative to an unridged surface for various ridged surfaces as a function of the wind velocity.

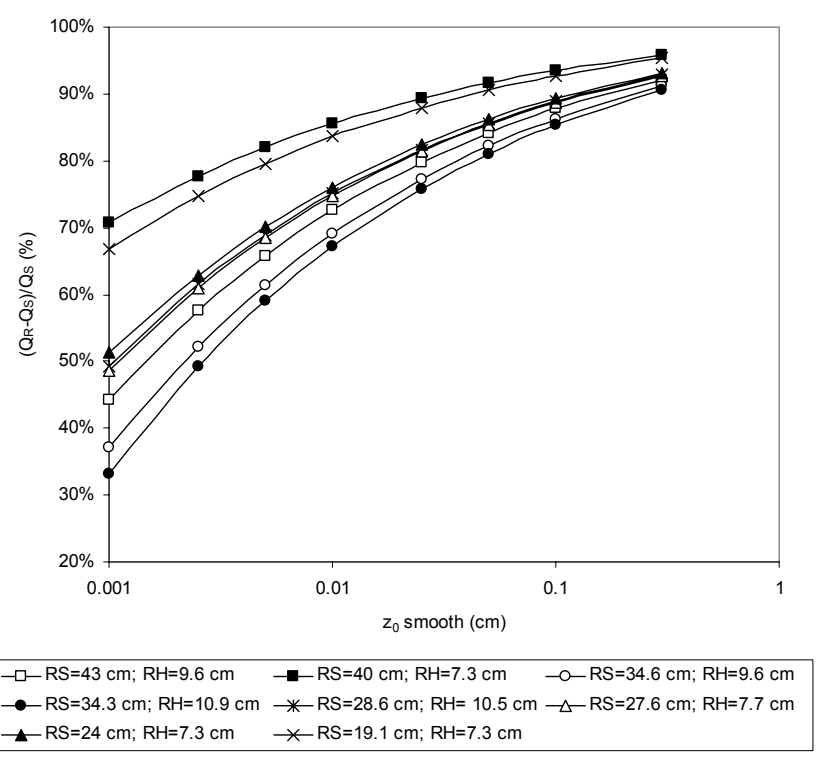

Fig. 12. Sensitivity of the erosion flux reduction over ridged surfaces to the roughness length of the corresponding smooth surface, for a wind velocity $=14 \mathrm{~m} . \mathrm{s}^{-1}$.

By plotting the ratio $\left(Q_{s}-Q_{r}\right) / Q_{s}$ versus the mean wind velocity $u$ calculated at a height $z=10 \mathrm{~m}$ (Fig. 11), we can observe that all ridged surfaces lead to an important relative reduction in the horizontal fluxes. This reduction reaches, for wind velocities greater than $14 \mathrm{~m} . \mathrm{s}^{-1}$, values ranging between 65 and $85 \%$, regardless of the height and spacing of the ridges. Otherwise, the total reduction in horizontal fluxes depends strongly on the value of the horizontal flux of the unridged surface, which is also strongly depending on its aerodynamic roughness length, $z_{0 S}$. Figure 12 shows that the total reduction in the horizontal flux increases when $z_{0 S}$ increases. Moreover, for low $z_{0 S}$, the various configurations exhibit different behaviors but when $z_{0 S}$ reaches a value of about $0.3 \mathrm{~cm}$, the horizontal flux reduction tends towards a unique value (close to $90 \%$ ), regardless of the ridge configurations. 
Table 6. Flux reduction due to geometric characteristic of ridges.

\begin{tabular}{cccc}
\hline $\begin{array}{c}R S \\
(\mathrm{~cm})\end{array}$ & $\begin{array}{c}R H \\
(\mathrm{~cm})\end{array}$ & $a_{S} / a_{r}$ & $\begin{array}{c}\text { Flux reduction }\left(1-a_{r} / a_{S}\right) \\
(\%)\end{array}$ \\
\hline 43 & 9.6 & 20 & $95.0 \%$ \\
40 & 7.3 & 17 & $94.1 \%$ \\
34.6 & 9.6 & 26 & $96.2 \%$ \\
34.3 & 10.9 & 34 & $97.1 \%$ \\
28.6 & 10.5 & 55 & $98.2 \%$ \\
27.6 & 7.7 & 26 & $96.2 \%$ \\
24 & 7.3 & 31 & $96.8 \%$ \\
19.1 & 7.3 & 68 & $98.5 \%$ \\
\hline
\end{tabular}

3.3.2 Geometric vs. aerodynamic effects on horizontal flux reductions

When transforming a smooth surface into a ridged one, changes in wind erosion horizontal fluxes result from a change in both aerodynamic parameters $\left(u_{*}, u_{* t}\right)$, mainly due to changes in $z_{0}$, and in the value of the coefficient $a$ (Eq. 10), which expresses the efficiency of a surface submitted to given aerodynamic conditions to produce saltating particles. These changes can be evaluated in terms of the ratio between the wind erosion horizontal fluxes over ridged surface $Q_{r}$ and the wind erosion horizontal fluxes over unridged surface $Q_{s}$, simulated by the developed parameterization for the same wind velocities:

$Q_{r} / Q_{s}=\left(a_{r} / a_{s}\right) \cdot\left[u_{* r}^{2} .\left(u_{* r}-u_{* t r}\right) / u_{* s}^{2} \cdot\left(u_{* s}-u_{* t s}\right)\right]$

The efficiency of ridges in reducing wind erosion increases (decreases) with the decreasing (increasing) $Q_{r} / Q_{s}$. Obviously, when this ratio becomes equal to 1 , the ridges have no effect on the wind erosion fluxes.

The ratio of coefficients $a_{s} / a_{r}$ quantifies only the wind erosion fluxes reduction due to the trapping of particles in the furrow's bottom, which is directly dependent on the geometric characteristics of the ridges (without accounting for any aerodynamic effect). The ratio $\left[u_{* r}^{2} \cdot\left(u_{* r}-u_{* t r}\right)\right] /\left[u_{* s}^{2} \cdot\left(u_{* s}-u_{* t s}\right)\right]$ assesses only the aerodynamic effect induced by the ridge's roughness on the horizontal fluxes.

The simulations show that the geometric effect $\left(a_{s} / a_{r}\right)$ reduces wind erosion horizontal fluxes by at least $94 \%$ ( 94 to $98.5 \%$, depending on ridge configurations) which means that the horizontal fluxes over the ridged surfaces are reduced by a factor of 17 to 68 compared to those over the smooth surface (Table 6). This suggests that the geometric effect is probably the dominant process in limiting wind erosion over ridged surfaces mainly by the trapping of saltating grains in the inter-ridge areas and perhaps by the reduction of the surface exposed to wind erosion resulting from the shape of the ridges.

As mentioned above, the aerodynamic effect on the wind erosion horizontal fluxes can be evaluated using the ratio $\left[u_{* r}^{2} \cdot\left(u_{* r}-u_{* t r}\right)\right] /\left[u_{* s}^{2} \cdot\left(u_{* s}-u_{* t s}\right)\right]$. A ratio greater
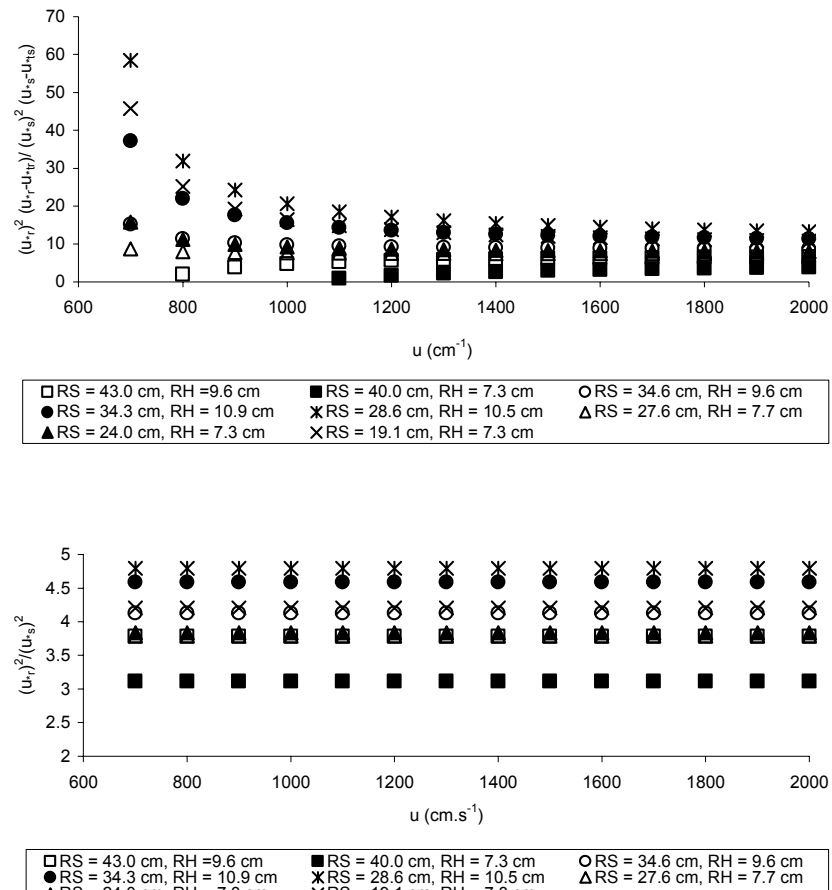
RS $=34.3 \mathrm{~cm}, \mathrm{RH}=10.9 \mathrm{~cm} \quad * \mathrm{RS}=28.6 \mathrm{~cm}, \mathrm{RH}=10.5 \mathrm{~cm}$ $\Delta \mathrm{RS}=27.6 \mathrm{~cm}, \mathrm{RH}=7.7 \mathrm{~cm}$

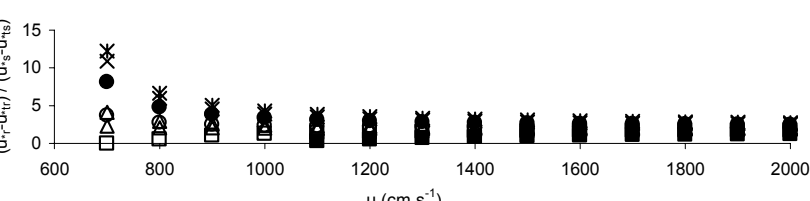

$\mathrm{u}\left(\mathrm{cm} \cdot \mathrm{s}^{-1}\right)$

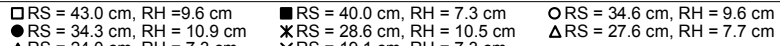

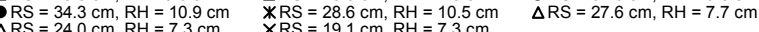

Fig. 13. Increases in wind erosion horizontal fluxes due to the aerodynamic effect, (a) total aerodynamic effect, (b) $\left[\left(u_{* s}\right)^{2} /\left(u_{* r}\right)^{2}\right]$, (c) $\left(u_{* s}-u_{* t s}\right) /\left(u_{* r}-u_{* t r}\right)$ (see text for details)

(lower) than 1 indicates greater (lower) horizontal flux over the ridged surface and thus the roughness leads to an increase (decrease) in soil erosion.

The simulations clearly show that the roughness effect always leads to an increase in the soil wind erosion fluxes, regardless of the ridge geometric characteristics (Fig. 13a). This behaviour was expected, since, for the same wind velocity at a height $z$, the roughness induced by ridges contributes to an increase in the wind friction velocity $\left(u_{*}\right)$ and, in accordance with Eq. (3), in the horizontal flux.

For each ridge configuration, the ratio $\left[\left(u_{* r}\right)^{2} /\left(u_{* s}\right)^{2}\right]$ is constant (Fig. 13b), hence the aerodynamic effect is mainly controlled by the ratio $\left(u_{* r}-u_{* t r}\right) /\left(u_{* s}-u_{* t s}\right)$ (Fig. 13c).

Figure 13a also shows that the aerodynamic effect is more significant at low wind velocities (about 7-8 $\mathrm{m} . \mathrm{s}^{-1}$ ), especially for the ridge configurations having low wind threshold friction velocities (less than $30 \mathrm{~cm} \cdot \mathrm{s}^{-1}$ ). In this case, the ratio $\left(u_{* r}-u_{* t r}\right) /\left(u_{* s}-u_{* t s}\right)$ has the highest values (8.112.2), leading the wind erosion fluxes to increase by a factor 

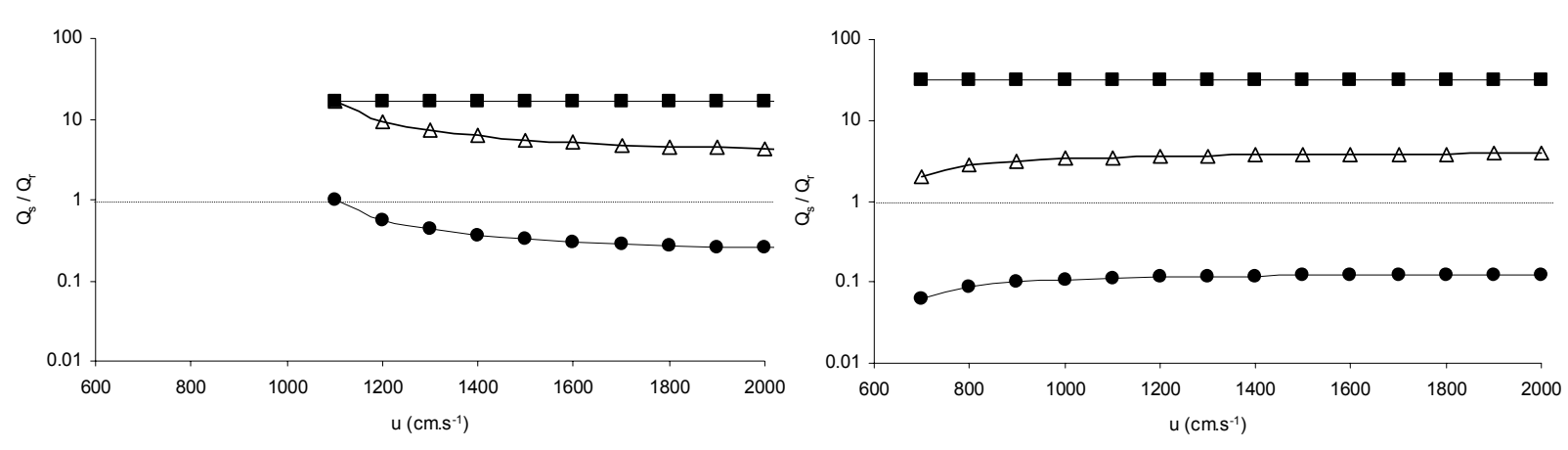

$\multimap$ Aerodynamic Effect $\rightarrow$ Trapping effect $\triangle$ Cumulated effect

$R S=43 \mathrm{~cm}, R H=9.6 \mathrm{~cm}$

$\multimap-$ Aerodynamic Effect $\rightarrow-$ Trapping effect $\triangle$ Cumulated effect

$$
R S=34.3 \mathrm{~cm}, R H=10.9 \mathrm{~cm}
$$
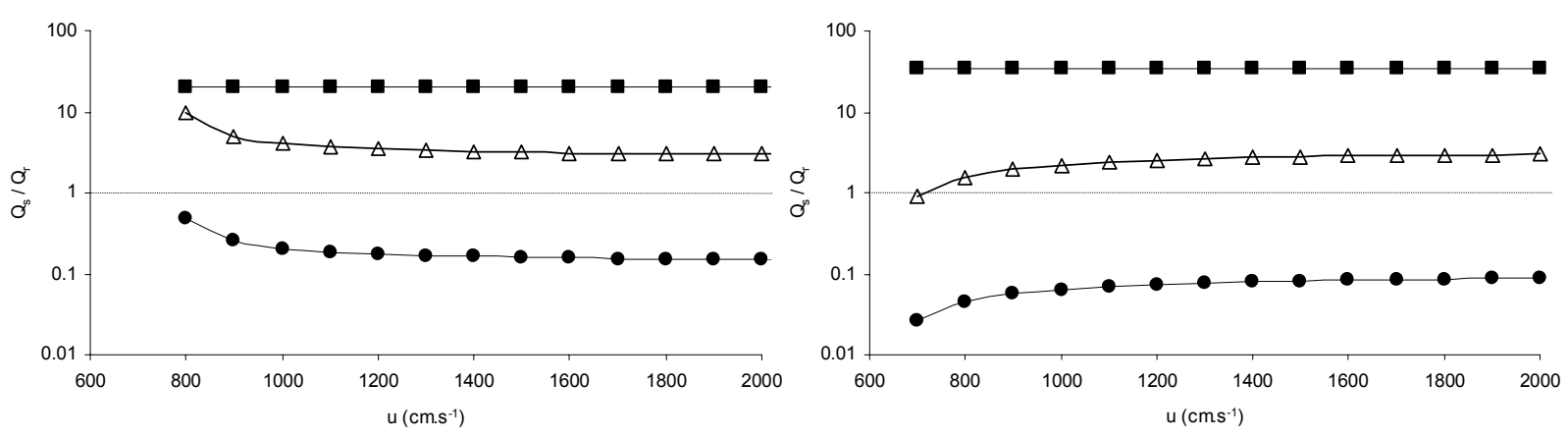

$\rightarrow$ Aerodynamic Effect $\rightarrow$ Trapping effect $\triangle$ Cumulated effect

$R S=27.6 \mathrm{~cm}, R H=7.7 \mathrm{~cm}$

$\multimap$ Aerodynamic Effect $\longrightarrow$ Trapping effect $\neg$ Cumulated effect

$R S=19.1 \mathrm{~cm}, R H=7.3 \mathrm{~cm}$
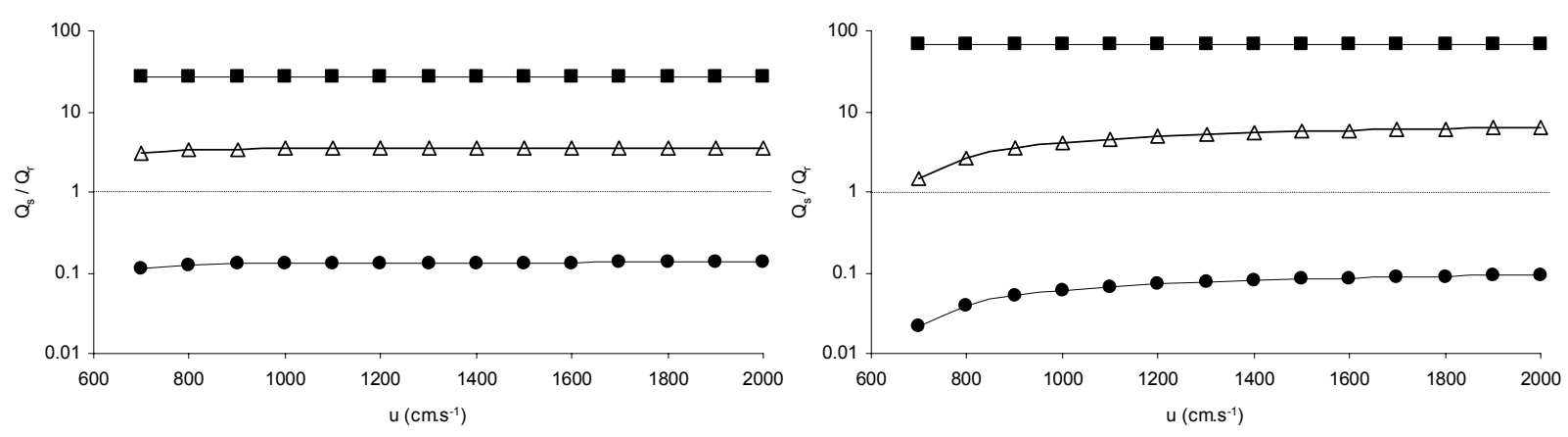

$\bullet$ Aerodynamic Effect $\rightarrow$ Trapping effect $\triangle$ Cumulated effect

$R S=34.6 \mathrm{~cm}, R H=9.6 \mathrm{~cm}$

$\bullet$ Aerodynamic Effect $\rightarrow$ Trapping effect $\triangle \triangle$ Cumulated effect

$R S=28.6 \mathrm{~cm}, R H=10.5 \mathrm{~cm}$
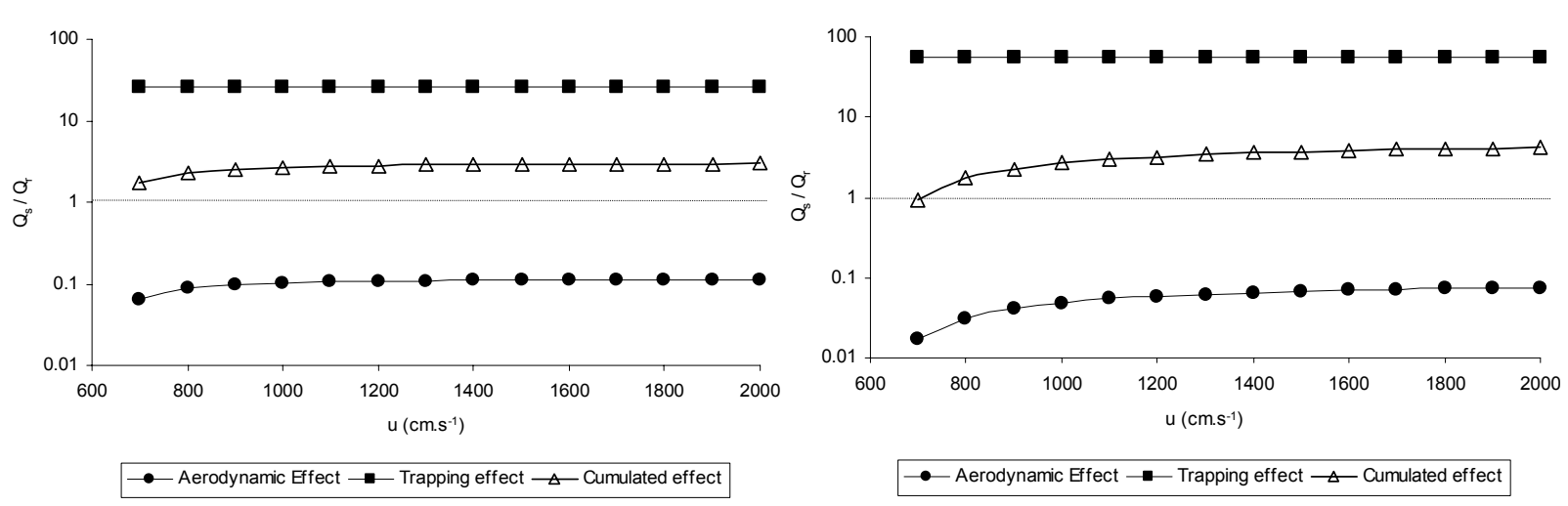

$\bullet$ Aerodynamic Effect $\longrightarrow$ Trapping effect $\triangle$ Cumulated effect

$\multimap$ Aerodynamic Effect $\longrightarrow$ Trapping effect $\triangle$ - Cumulated effect

Fig. 14. Geometric and aerodynamic effects on horizontal flux reduction over ridged surfaces. 
reaching 60 .

For all the other ridge configurations, the increase in wind erosion fluxes induced by the aerodynamic roughness effect is almost similar, between 12 to 15 times the wind erosion fluxes over an unridged surface, regardless of the wind velocity. However the aerodynamic effect remains generally weak and compensates only for a part of the reduction in horizontal fluxes due to the geometric characteristics of the ridges (Fig. 14).

\section{Summary and conclusion}

In order to evaluate horizontal fluxes produced by wind over ridged surfaces, eight-ridge configurations, representative of those observed in Tunisia, with $R H / R S$ ranging from 0.18 to 0.38 , were experimented in a wind tunnel. From these experiments, we derived a parameterization which allows one to predict horizontal fluxes over ridged surfaces only from ridge heights $(R H)$, ridge spacing $(R S)$ and wind velocity. This parameterization was tested using both additional experimental data sets and data from the literature. In both cases, calculated and measured values are in satisfactory agreement, suggesting that the proposed parameterization may be used to predict wind erosion over dry farming areas. This parameterization was then used to evaluate the efficiency of ridges in reducing wind erosion. Results show that, when compared to an unridged surface, ridged surfaces lead to an important relative reduction in horizontal fluxes, always exceeding $60 \%$. For each tested ridge configuration, the reduction tends towards a constant value when the wind velocity increases. Otherwise, the total relative reduction in wind erosion depends strongly on the horizontal flux measured on the unridged surface and therefore on the smooth aerodynamic roughness length $\left(z_{0 s}\right)$. Our simulations suggest that the relative total reduction in the horizontal flux is greater for an initial smooth surface having a higher $z_{0 s}$.

All the experimented ridge configurations lead to a very strong reduction in the horizontal fluxes compared to those computed for an equivalent smooth surface. Moreover, it appears that small ridges, with $R S$ of about $20 \mathrm{~cm}$, are the most efficient to limit wind erosion. The results also showed that the geometric effect of the ridges (probably by trapping saltating particles) is the main process acting in the horizontal flux reduction over ridged surfaces. It strongly dominates the aerodynamic effect induced by the ridge roughness, which increases the horizontal fluxes but not sufficiently to compensate for the geometric effect.

Hence, it should be noted that the results obtained suggest that the proposed parameterization, which only requires the geometric characteristics of ridges (ridges height and spacing) and mean wind velocity as input data, is well suited to both predict the wind erosion fluxes over ridged surfaces of arid and semi-arid regions and for designing and recommending tillage tools that could reduce wind erosion susceptibility.
Finally, although the proposed model was validated using additional experimental data sets and data from the literature, measurements from field experiments are required to confirm its consistency. However, it should be noted that, since the model was tested using tilled ridge conditions of North African agricultural fields, it would be especially appropriate for computing horizontal dust flux in semi-arid areas.

Acknowledgements. Topical Editor F. D'Andréa thanks G. Cautenet and V. Lopez for their help in evaluating this paper.

\section{References}

Arika, C. L., Gregoy, J. M., Borrelli, J., and Zartman, R. E.: A ridge and clod wind erosion model, ASAE Paper, No. 86-2531, St. Joseph, MI., 1986.

Armbrust, D. V., Chepil, W. S., and Siddoway, F. H.: Effects of ridges on erosion of soil by wind, Soil Sci. Soc. Am. Proc., 28, 557-560, 1964.

Bagnold, R. A.: The physics of blow sand and desert dunes, Methuen, London, 265 pp., 1941.

Chepil, W. S. and Woodruff, N. P.: The physics of wind erosion and its control, Advances in Agronomy, 15, 211-302, 1963.

Chepil, W. S.: Influence of moisture on erodibility of soil by wind, Soil Sci. Soc. Am. Proc., 20, 288-292, 1956.

Fryrear, D. W.: Soil ridge-clods and wind erosion, Trans. ASAE, 27, 445-448, 1984.

Fryrear, D. W. and Skidmore, E. L.: Methods for controlling wind erosion, in: Soil erosion and crop productivity, edited by: Follet, R. F. and Stewart, B. A., ASA-CSSA-SSSA, Madison, WI., 443457, 1985.

Fryrear, D. W.: Soil cover and wind erosion, Trans. ASAE, 28, 781784, 1985.

Gillette, D. A. and Stockton, P. H.: The effect of nonerodible particles on wind erosion of erodible surfaces, J. Geophys. Res., 94, 12 885-12 893, 1989.

Gillette, D. A.: Environmental factors affecting dust emission by wind erosion, in: Saharan Dust, edited by: Morales, C., J. Wiley and Sons, New-York, 71-94, 1979.

Gillette, D. A.: On the production of soil wind erosion aerosols having the potential for long range transport, J. Rech. Atm., 8, 735-744, 1974.

Greeley, R., and Iversen, J. D.: Wind as a geological process on Earth, Mars, Venus and Titan, Cambridge University Press, Cambridge, 333 pp, 1985.

Hagen, L. J. and Armbrust, D. V.: Aerodynamic roughness and saltation trapping efficiency of tillage ridges, Trans. ASAE, 35, 1179-1184, 1992.

Hagen, L. J.: Assessment of wind erosion parameters using wind tunnels, pp. 742-746, in: Sustaining the Global Farm, edited by: Stott, D. E., Mohtar, R. H., and Steinhardt, G. C., Selected papers from the 10th International Soil Conservation Organization Meeting held 24-29 May 1999 at Purdue University and the USDA-ARS National Soil Erosion Research Laboratory, 2001.

Kardous, M., Bergametti, G., and Marticorena, B.: Aerodynamic roughness length related to non-aggregated tillage ridges, Ann. Geophys., 23, 3187-3193, 2005.

Lettau, K. and Lettau, H. H.: Experimental and micrometeorological field studies of dune migration, in: Exploring the World's Driest Climate, Lettau, H. H. and Lettau, K., University 
of Wisconsin-Madison, Institute for Environmental Studies, IES Report 101, 110-147, 1978.

Leys, J. F. and Raupach, M. R.: Soil flux measurements with a portable wind erosion tunnel, Aust. J. Soil Res., 29, 533-552, 1991.

Monin, A. S.: Boundary layers in planetary atmospheres, in: Dynamic Meteorology, edited by: Morel, P., D. Reidel Publishing Company, Boston, 419-458, 1973.

Panofsky, H. A. and Dutton, J. A.: Atmospheric turbulence: Models and methods for engineering applications, Wiley and Sons, New York, 397 pp., 1984.

Pimentel, D., Harvey, C., Resosudarmo, P., Sinclair, K., Kurz, D., McNoir, M., Crist, S., Shpritz, L., Fitton, L., Saffouri R., and Blair, R.: Environmental and economic costs of erosion and conservation benefits, Science, 267, 1117-1123, 1995.
Saxton, K. E.: Wind erosion and its impact on off-site air quality in the Columbia Plateau: an integrated research plan, Trans. ASAE, 38, 1031-1038, 1995.

Shao, Y., Raupach, M. R., and Findlater, P. A.: Effect of saltation bombardment on the entrainment of dust by wind, J. Geophys. Res., 98, 12 719-12 726, 1993.

Sörensen, M.: Estimation of some aeolian saltation transport parameters from transport rate profiles, in: Proccedings of the International Workshop on the Physics of Blown Sand, edited by: Barndorff-Nielsen, O. E., Möller, J. T., Rasmussen, K., and Willets, B. B., University of Aarhus, Aarhus, Denmark, 141-190, 1985.

Williams, G.: Some aspects of the aeolian saltation load, Sedimentology, 3, 257-287, 1964. 